Jurnal Pemberdayaan: Publikasi Hasil Pengabdian kepada Masyarakat

Vol. 2, No. 3, Desember 2018, Hal. 393-398

ISSN: 2088 4559; e-ISSN: XXXX-XXXX

DOI:

\title{
PELATIHAN APOTEKER CILIK UNTUK SISWA SD KELAS 5 DI WILAYAH SENTOLO, KULON PROGO
}

\author{
Nining Sugihartini ${ }^{1}$, Hendi Ristiono $^{2}$, Tedjo Yuwono ${ }^{3}$ \\ Universitas Ahmad Dahlan, Yogyakarta ${ }^{1,2,3}$ \\ Email: nining.sugihartini@pharm.uad.ac.id ${ }^{1}$
}

\begin{abstract}
ABSTRAK
Penggunaan obat khususnya pada anak-anak perlu mendapatkan perhatian khusus karena tidak semua anak mudah minum obat ketika sakit. Di sisi lain masa anak-anak perlu mendapatkan banyak informasi tentang berbagai profesi agar dapat menambah wawasan sekaligus memacu semangat belajar. Berdasarkan hal tersebut maka dilakukan pelatihan apoteker cilik kepada siswa SD yang bertujuan untuk mengenalkan profesi Apoteker, mengenalkan berbagai macam jenis obat serta penggunaannya yang baik dan benar. Pelatihan dilakukan pada siswa SD kelas 5 di wilayah Sentolo meliputi SDN Inpres Gembongan, SD Muhammadiyah Wora-Wari dan SD MI Muhammadiyah Kenteng. Kegiatan tersebut dibantu oleh 4 mahasiswa S1 Farmasi yang diawali dengan penjelasan di kelas. Setelah itu dilanjutkan dengan lomba mewarnai seorang apoteker, berlatih menggerus serta membungkus puyer yang telah dihasilkan. Pada kegiatan tersebut semua anak-anak terlihat antusias yang menunjukkan bahwa mereka tertarik dengan profesi Apoteker. Pada akhir kegiatan mereka menyampaikan bahwa ketika sakit harus minum obat sesuai ketentuan dokter serta ada beberapa yang kemudian tertarik menjadi Apoteker.
\end{abstract}

Kata kunci: Apoteker Cilik, Pelatihan, Siswa SD

\begin{abstract}
The use of drugs, especially in children, needs special attention because not all children easily take medicine when they are sick. On the other hand the childhood needs to get a lot of information about various professions in order to be able to add insight while spurring the spirit of learning. Based on this, a little pharmacist is trained to elementary school students who aim to introduce the Pharmacist profession, introduce various types of drugs and their use is good and right. The training was conducted on 5th grade elementary school students in the Sentolo area including the Gembongan SDN Inpres, SD Muhammadiyah Wora-Wari and SD MI Muhammadiyah Kenteng. The activity was assisted by 4 udergraduate student in Pharmacy program study starting with an explanation in class. After that, it continued with the coloring contest of a pharmacist, practicing the grinding and wrapping the powder that had been produced. In this activity all the children looked enthusiastic showing that they were interested in the Pharmacist profession. At the end of the activity they said that when sick they had to take medication according to the doctor's provisions and there were some who were later interested in becoming Pharmacists.
\end{abstract}

Keywords: Little Pharmacist, Training, Elementary School Students 


\section{PENDAHULUAN}

Era globalisasi menyebabkan arus informasi maupun barang sangat deras masuk ke Indonesia. Salah satu barang yang banyak masuk adalah beraneka-ragamnya jajanan anakanak. Pemerintah telah berusaha untuk melindungi konsumen khususnya anak-anak dengan sennatiasa melakukan pengawasan dan pengecekan. Namun demikian masih ada beberapa pihak yang tidak bertanggungjawab yang memasukkan bahan tambahan pangan berbahaya ke jajanan anak-anak. Kurangnya pemahaman akan bahaya bahan berbahya dan masih rentannya kondisi kesehatan anak-anak menyebabkan anak-anak sangat mudah mengalami gangguan kesehatan karena jajanan yang tidak sehat tersebut. Bahan berbahaya yang sering ada dalam jajanan anak-anak adalah formalin, boraks, dan rhodamin B. Hasil penelitian telah menunjukkan bahwa 40-44\% jajanan anak tidak memenuhi ketentuan kesehatan (Paratmanitya \& Aprilia, 2016; Fajar, 2015). Selain itu, anak-anak juga terkadang masih sulit untuk minum obat. Sehingga, perlu berbagai upaya untuk meningkatkan pengetahuan anakanak tentang efek bahan berbahaya dalam jajanan.

Berdasarkan hal tersebut maka diadakan Pelatihan Apoteker Cilik di SD N Gembongan, MI Kenteng dan SD Muhammadiyah Wora-Wari di Kecamatan Sentolo. Dengan adanya kegiatan tersebut maka diharapkan pengetahuan siswa SD khususnya kelas 5 tentang bahan berbahaya dalam jajanan bisa meningkat sehingga akan lebih berhati-hati dalam memilih jajanan. Selain itu dalam pelatihan juga diberikan ketrampilan meracik obat dari Vitamin sehingga diharapkan akan menambah wawasan siswa SD tentang berbagai alternatif profesi yang dapat dipilih di masa yang akan datang.

\section{METODE}

\section{Alat dan Bahan}

Alat yang digunakan meliputi proyektor, LCD, mortir dan stamfer. Bahan yang digunakan meliputi Vitamin C, kertas puyer, kertas gambar dan pewarna gambar.

\section{Jalannya Pengabdian}

Kegiatan ini dilaksanakan dalam 5 tahapan yang meliputi tahap persiapan, pelaksanaan kegiatan di SD N Gembongan, SD Muhammadiyah Wora-Wari dan SD MI Kenteng serta tahapan evaluasi seperti yang disajikan pada Tabel 1. 
Tabel 1. Rincian kegiatan pengabdian masyarakat dengan tema pelatihan Apoteker Cilik siswa SD kelas 5 di wilayah Sentolo

\begin{tabular}{|c|c|c|}
\hline No & Waktu & Kegiatan \\
\hline \multirow[t]{6}{*}{ A. } & Kegiatan 1 & 8.00-8.45 : Perjalanan ke Sentolo \\
\hline & Senin, 19 Maret 2018 & 8.45-09.45: Diskusi dg pengelola SD N Gembongan tentang pelaksanaan \\
\hline & Durasi : 4 jam 30 menit & pelatihan meliputi tanggal, jam dan metode pelatihan \\
\hline & & $\begin{array}{l}\text { 09.45-10.45: Diskusi dg pengelola SD Muhammadiyah Wora-Wari } \\
\text { tentang pelaksanaan pelatihan meliputi tanggal, jam dan } \\
\text { metode pelatihan }\end{array}$ \\
\hline & & $\begin{array}{l}\text { 10.45-11.45: Diskusi dg pengelola MI Muhammadiyah Kenteng tentang } \\
\text { pelaksanaan pelatihan meliputi tanggal, jam dan metode } \\
\text { pelatihan }\end{array}$ \\
\hline & & 11.45-12.30: Perjalanan pulang \\
\hline \multirow[t]{7}{*}{ B. } & Kegiatan 2 & 7.15-8.00 : Perjalanan ke SD N Gembongan \\
\hline & Selasa, 27 Maret 2018 & 8.00-09.00 :Ceramah tentang macam-macam obat dan efek bahan \\
\hline & Durasi: 5 jam 30 menit & berbahaya pada jajanan \\
\hline & & 09.00-10.00: Pelatihan penggunaan obat yang baik dan benar \\
\hline & & 10.00-11.00: Pengenalan profil kerja apoteker \\
\hline & & 11.00-12.00: Pelatihan menggerus dan mengemas Vitamin dalam puyer \\
\hline & & 12.00-12.45: Perjalanan pulang \\
\hline \multirow[t]{7}{*}{$\mathrm{C}$. } & Kegiatan 3 & 7.15-8.00 : Perjalanan ke SD Muhammadiyah Wora-wari \\
\hline & Rabu, 28 Maret 2018 & 8.00-09.00 :Ceramah tentang macam-macam obat dan efek bahan \\
\hline & Durasi: 5 jam 30 menit & berbahaya pada jajanan \\
\hline & & 09.00-10.00: Pelatihan penggunaan obat yang baik dan benar \\
\hline & & 10.00-11.00: Pengenalan profil kerja apoteker \\
\hline & & 11.00-12.00: Pelatihan menggerus dan mengemas Vitamin dalam puyer \\
\hline & & 12.00-12.45: Perjalanan pulang \\
\hline \multirow[t]{6}{*}{ D. } & Kegiatan 4 & 7.15-8.00 : Perjalanan ke MI Muhammadiyah kenteng \\
\hline & Kamis, 29 Maret 2018 & 8.00-09.00: Ceramah tentang efek bahan berbahaya pada jajanan \\
\hline & Durasi: 5 jam 30 menit & 09.00-10.00: Pelatihan penggunaan obat yang baik dan benar \\
\hline & & 10.00-11.00: Pelatihan khasiat tanaman obat \\
\hline & & 11.00-12.00: Pengenalan alat kesehatan \\
\hline & & 12.00-12.45: Perjalanan pulang \\
\hline \multirow[t]{3}{*}{ E. } & Kegiatan 5 & 8.00-8.45 : Perjalanan ke Sentolo \\
\hline & Senin, 9 April 2018 & 8.45-09.35: Diskusi dg pengelola SD N Gembongan tentang evaluasi \\
\hline & Durasi: 4 jam & kegiatan dan rencana tindak lanjut berdasarkan hasil \\
\hline
\end{tabular}


pelatihan

09.35-10.25: Diskusi dg pengelola SD Muhammadiyah Wora-Wari tentang evaluasi kegiatan dan rencana tindak lanjut berdasarkan hasil pelatihan

10.25-11.15: Diskusi dg pengelola MI Muhammadiyah Kenteng tentang evaluasi kegiatan dan rencana tindak lanjut berdasarkan hasil pelatihan

11.15-12.00: Perjalanan pulang

\section{HASIL, PEMBAHASAN, DAN DAMPAK}

Kegiatan pelatihan Apoteker cilik pada siswa SD diawali dengan pemberian ceramah mengenai jenis-jenis obat yang ada di pasaran dan cara penggunaan obat yang baik dan benar. Selain itu siswa diajak diskusi mengenai beragam profesi yang menjadi cita-cita mereka. Berdasarkan hasil diskusi tersebut ternyata sedikit saja siswa SD yang mengenal profesi Apoteker. Kegiatan kemudian dilanjutkan dengan pengenalan profesi Apoteker melalui aktivitas lomba menggambar serta menggerus dan mmebungkus vitamin. Kegiatan tersebut disambut antusias oleh Siswa SD karena dekat dengan kegiatan sehari-hari di sekolah yaitu mewarnai gambar. Apalagi saat mendapatkan pengalaman meracik obat dengan menggunakan mortir dan stamfer mereka terlihat sangat antusias. Kegiatan tersebut dilakukan secara berkelompok namun setiap siswa tetap diberikan kesempatan untuk menggerus dan membungkus. Hasil membungkus puyer diserahkan kepada pendamping yang merupakan mahasiswa S1 Farmasi yaitu Januar Bayu Syamsudin, Erri Andang Prasetiantoro, Hasbi asshiddiq dan Zein Domir Hakiki. Pada akhir kegiatan diberikan hadiah lomba mewarnai seperti yang disajikan pada gambar 1. Selain itu juga dilakukan diskusi lagi tentang profesi Apoteker. Mereka menyampaikan bahwa mereka menjadi lebih mengenal profesi Apoteker sehingga bertambah jumlah siswa SD yang berminat menjadi Apoteker. Selain itu juga mereka menjadi lebih paham bahwa ketika sakit harus minum obat sesuai anjuran dokter serta lebih berhati-hati dalam memilih jajanan agar tidak mudah sakit. 


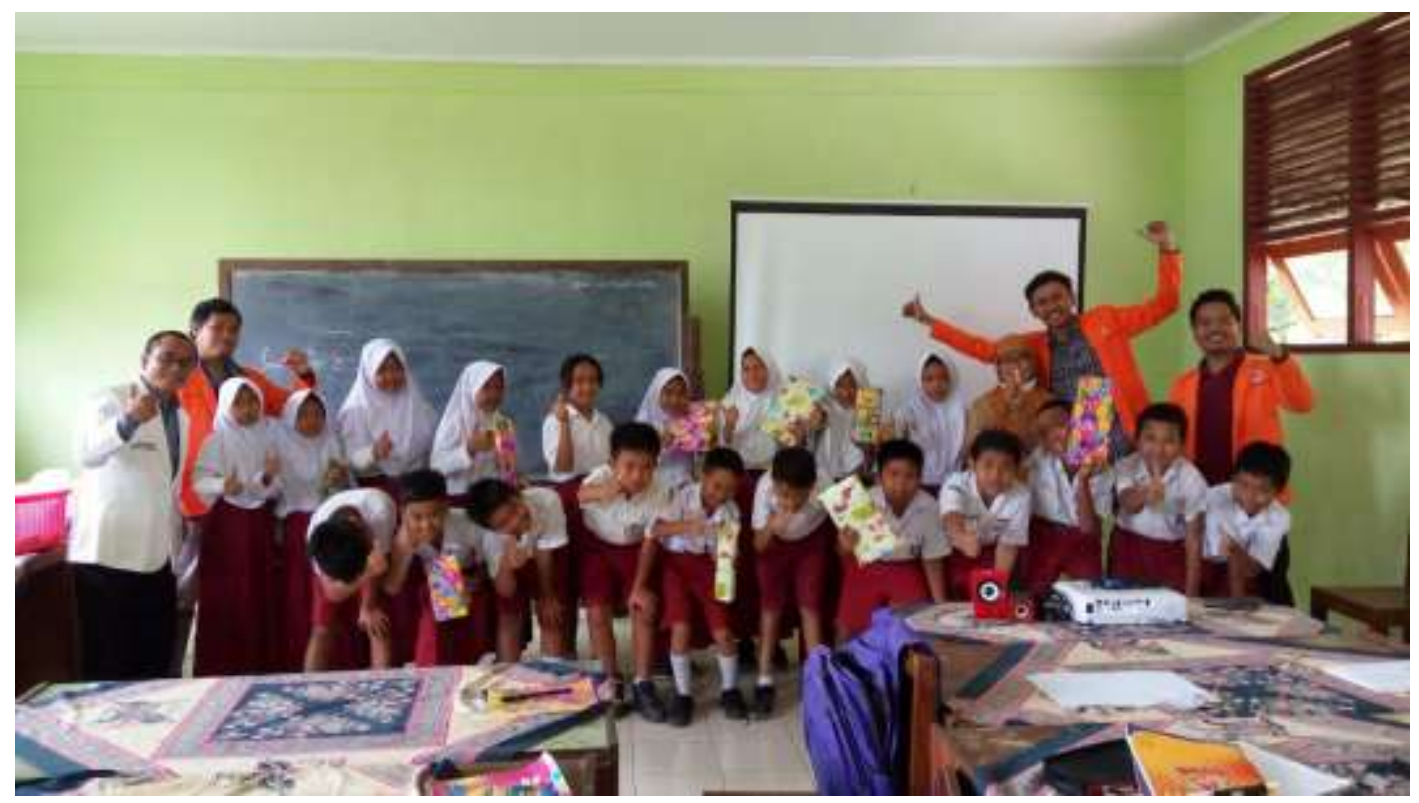

Gambar 1. Foto bersama pendamping, guru dan siswa SD di SDN Gembongan saat kegiatan pelatihan Apoteker cilik

\section{SIMPULAN}

Siswa SD menjadi lebih berhati-hati dalam memilih jajanan yang akan dikonsumsi dan lebih mengenal profesi Apoteker.

\section{UCAPAN TERIMAKASIH}

Kegiatan pengabdian kepada masyarakat ini terselenggara atas bantuan dana Hibah Pengabdian Masyarakat dari LPPM UAD dengan nomor kontrak L2/SPK-PPM-21/LPTTUAD/I/2018. Juga kepada tim mahasiswa S1 Farmasi yang telah banyak membantu yaitu Januar Bayu Syamsudin, Erri Andang Prasetiantoro, Hasbi As-shiddiq dan Zein Domir Hakiki.

\section{DAFTAR PUSTAKA}

Fajar, A. (2015). Perlindungan Konsumen terhadap Penggunaan Zat Aditif pada Makanan. Skripsi. Makassar: Universitas Hasanudin.

Paramamitya, Y., \& Aprilia, V. (2016). Kandungan Bahan Tambahan Pangan Berbahaya pada Makanan Jajanan Ana Sekolah Dasar di Kabupaten Bantul. Jurnal Gizi dan Dietetik Indonesia, 4(1), 49-55. 
